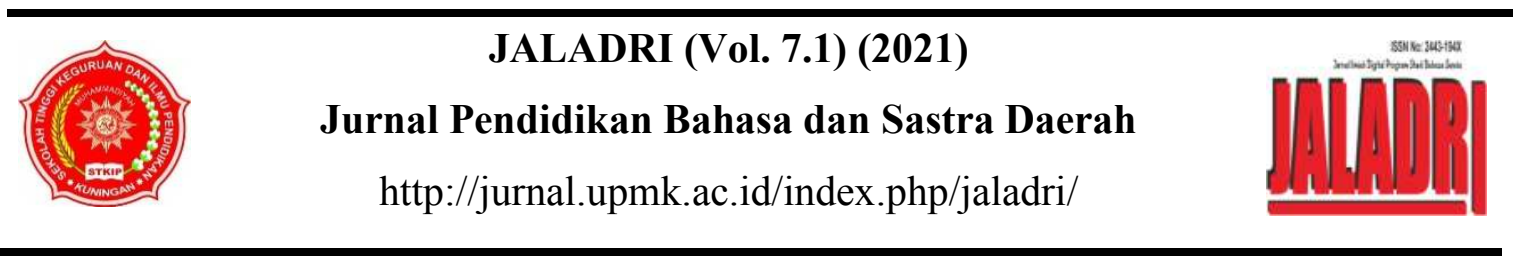

\title{
KAJIAN STRUKTURAL DAN ANTROPOLOGI SASTRATERHADAP NOVEL MUNJUNG KARYA MOH. AMBRI
}

\section{Yusuf Ramdani}

yusufrdani@student.upi.edu

MGMP Bahasa Sunda SMA Kota Sukabumi

\section{Info Artikel}

Sejarah Artikel:

Diterima 10 Januari 2021

Disetujui 10 April 2021

Dipublikasikan 21 April 2021

Kata Kunci:

karya sastra,

kebudayaan, novel.

\begin{abstract}
Abstrak
Penelitian ini dilatarbelakangi perlunya perngkajian unsur antropologi sastra dalam karya sastra, khususnya untuk pembaca. Untuk mengetahui budaya masarakat tidak perlu terjun langsung ke lapangan, tapi bisa dengan cara mengkaji karya sastra yang ada melalui sudut pandang kebudayaan yang tumbuh dan berkembang di masyarakat. Hubungan antara kebudayaan dan adat-istiadat merupakan pola hidup masyarakat yang turun-temurun lahir dari nenek moyang. Adanya kebudayaan tersebut merupakan latar belakang masarakat yang masih percaya dengan kebudayaan tersebut kemudian terus berkembang dan disalah gunakan. Tujuan dari penelitian ini adalah untuk mendeskripsikan novel, struktur cerita dan unsur antropologi sastra dari novel Munjung karya Moh. Ambri. Metode yang digunakan dalam penelitian ini adalah metode deskriptif yang secara langsung mendeskripsikan unsur antroplogi sastra di dalamnya, sedangkan teknik pengumpulan data menggunakan studi pustaka dengan cara mengumpulkan sumber data berupa novel. Berdasarkan hasil penelitian, struktur cerita novel Munjung melingkupi tiga aspék, yaitu struktur tema, fakta cerita (alur, tokoh dan penokohan), dan sarana sastra (judul, sudut pandang, dan gaya bahasa). Téma umum dari novel ini adalah kekayaan dan pesugihan. Struktur penyajian berdasarkan antropologi sastra terdiri dari masa lampau, kearifan lokal, folklor (tradisi lisan dan sastra lisan), dan mitos. Unsur antropologis yang terkait dalam cerita novel tersebut adalah 1) masa lampau, masa yang sudah terjadi dan dialami oleh tokoh dalam novel Munjung, 2) kearifan lokal, yang terdiri dari kepercayaan masyarakat, agama, adat-istiadat, dan kebiasaan, 3) folklor (tradisi lisan dan sastra lisan), terdiri dari peribahasa, dialek, dan adat kebiasaan ritual, serta 4) mitos, takdir, masa lampau, dan kecurigaan.
\end{abstract}




\section{Abstrack}

This research is motivated by the absence of literary anthropology in literary works that need to be studied in order to be used for readers. To understand the culture of the community does not need to go directly to the field, but can by studying existing literary works through the perspective of culture that grows and develops in the community. The relationship between culture and customs is a pattern of life for generations born from ancestors. The existence of this culture is the background of people who still believe in that culture and then develop and be abused. The purpose of this study is to describe the novel, the structure of the story and the anthropological literature of the novel Munjung by Moh. Ambri. The method used in this research is descriptive method which directly describes it is not in accordance with the literature, while the data collection technique uses literature study by collecting data sources in the form of novels. Based on the results of the study, the novel structure of Munjung's story encompasses three aspects, namely the structure of themes, the facts of the story (plot, characters and characterizations), and literary means (title, point of view, and language style). The general theme of this novel is wealth and pesugihan. The structure of presentation based on literary anthropology consists of the past, local wisdom, folklore (oral traditions and oral literature), and legends. Anthropological elements related to this novel are 1) the past, the period that has occurred and experienced by the characters in the Munjung novel, 2) local wisdom, which consists of community beliefs, religion, customs, and habits, 3) folklore ( oral traditions and oral literature), consisting of proverbs, dialects, and rituals, customs, and 4) myths, destiny, past, and suspicion. 


\section{PENDAHULUAN}

Sastra merupakan gambaran kehidupan masryarakat sehari-hari yang berhubungan dengan budaya. Suatu karya sastra bisa dianalisis dengan cara menelaah isi cerita serta dikaitkan dengan unsur-unsur di luar karya sastra. Hal ini sesuai dengan pendapat Isnendes (2010: 10) bahwa isi karya sastra merupakan hasil dari pengalaman serta imajinasi dari pengarang.

Untuk mendalami budaya suatu masyarakat dapat ditempuh salah satunya dengan meneliti karya sastranya, yang menggambarkan pandangan-pandangan suatu kebudayaan yang tumbuh dan berkembang di masyarakat tertentu. Hal tersebut sesuai dengan yang dikemukakan oleh Djirong (2014: 215) bahwa sastra merupakan bagian integral yang mencakup kesenian, sedangkan kesenian itu sendiri merupakan bagian dari budaya. Oleh sebab itu, membaca karya sastra dikatakan Suherman (2019: 265) sebagai sebuah kegiatan literasi budaya. Berkaitan dengan hal tersebut Éndraswara (2013: 14) menjelaskan bahwa dimensi pluritas téks (sastra) menimbulkan ragam budaya. Sastra modern seperti novel, puisi/sajak, cerpen dan drama, juga sastra lama seperti babad, wawacan, dongeng, dan carita pantun, termasuk babasan dan paribasa, humor, sisindiran, beserta karya sastra lainnya merupakan objek penelitian yang kaya akan nilai kebudayaan.

Novel merupakan salah satu karya sastra yang membahas kehidupan manusia serta di dalamnya terdapat kebudayaan. Menurut Andriyani (2017: 4) novel adalah karangan prosa yang lebih panjang dari cerita pendek dan menceritakan kehidupan seseorang dengan lebih mendalam dengan menggunakan bahasa seharihari serta banyak membahas aspek kehidupan manusia. Nilai-nilai dalam novel bisa diteliti melalui antropologi sastra, yang menitikberatkan terhadap analisis karya sastra berdasarkan aspekaspek kabudayaan yang ada dalam karya tersebut (Ayuningtias, 2016: 3). Hubungan antara kebudayaan dan adat-istiadat merupakan pola hidup suatu masyarakat yang turun-temurun sudah ada sejak zaman nenek moyang. Perilaku, kebiasaan, mitos, dan tradisi yang ada di masyarakat biasanya diimajinasikan melalui karya sastra. Menurut (Wahyuningsi, 2018: 327) unsur yang tak lepas dari sebuah karya sastra adalah manusia dengan berbagai budayanya yang meliputi pengetahuan, kepercayaan, kesenian, dan moral, serta hukum dan adat-istiadat.
Dengan adanya budaya tersebut menjadi alasan masyarakat berpegang teguh terhadap tradisi leluhurnya serta terus dikembangkan dalam kehidupan. Dengan begitu muncul ide dalam meneliti kebiasaan tersebut, salah satunya melalui pendekatan antropologi sastra.

Penelitian antropologi sastra digunakan untuk menganalisis kebudayaan terhadap karya sastra secara antropologis. Pentingnya analisis unsur kabudayaan dalam karya sastra dikemukakan oleh Sudikan (2007: 13) bahwa antropologi sastra mutlak diperlukan sebagai perbandingan antara psikologi dan sosiologi sastra. Selain itu, antropologi sastra juga diperlukan dengan pertimbangan kekayaan kebudayaan seperti warisan dari leluhur. Pembahasan mengenai antropologi sastra berkaitan dengan tradisi, adat-istiadat, mitos, dan peristiwa-peristiwa kabudayaan pada umumnya, sebagai peristiwa yang khas berkaitan dengan kajadian-kajadian masa lampau atau masa yang sudah dilalui. Antropologi sastra terbagi menjadi empat unsur yaitu 1) masa lampau, masa yang sudah lewat atau sudah terjadi serta tidak bisa terulang kembali yang ada dalam cerita; 2) kearifan lokal, unsur-unsur estetis dievokasi melalui bahasa, majas dan gaya bahasa. Analisis sastra dikaji melalui bentuk yaitu bahasa, sedangkan analisis antropologis dilakukan melalui isi, yaitu muatan-muatan dalam cerita; 3 ) folklor (tradisi lisan dan sastra lisan), yaitu tradisi lisan dan sastra lisan yang ada dalam cerita; dan 4) mitos, yaitu legenda atau kepercayaan masarakat dalam masa penceritaan (Ratna, 2011: 79).

Dalam menganalisis novel, peneliti tidak hanya menggunakan pendekatan antropologi sastra, tetapi digunakan juga pendekatan struktural. Menurut Adam (2015: 2) pendekatan struktural merupakan suatu pendekatan dalam ilmu sastra yang cara kerjanya menganalisis unsur-unsur struktur yang membangun karya sastra dari dalam, serta mencari hubungan atau keterkaitan unsur-unsur yang satu dengan yang lain dalam rangka mencapai kebulatan makna. Bentuk unsur novel dianalisis dari struktur sastra menggunakan pendekatan struktural Robert Stanton yang meliputi tema, fakta cerita (alur, tokoh dan penokohan, serta latar), dan sarana sastra (judul, sudut pandang, dan gaya bahasa).

\section{METODE PENELITIAN}

Penelitian ini termasuk dalam penelitian kualitatif dengan menggunakan metode 
deskriptif. Metode deskriptif kualitatif adalah metode pengolahan data dengan cara menganalisa faktor-faktor yang berkaitan dengan objek penelitian dengan penyajian data secara lebih mendalam terhadap objek penelitian (Prabowo, 2013: 5).

Sumber data dalam penelitian ini adalah novel Munjung karya Moh. Ambri, yang diterbitkan oleh Kiblat Buku Utama Bandung, pada tahun 2003. Teknik pengumpulan data yang digunakan dalam penelitian ini adalah teknik studi pustaka. Studi pustaka biasanya disingkat kaji pustaka atau telaah pustaka (literature review), merupakan kegiatan mempelajari, menelaah dan mengidentifikasi pengetahuan (Arikunto, 2009: 58).

Langkah-langkah yang ditempuh dalam penelitian ini yaitu: 1) persiapan, peneliti merumuskan masalah dan instrumen, 2) mengumpulkan data, dengan cara menggunakan teknik studi pustaka, 3) mengolah, menganalisis, dan menafsirkan data, 4) membuat kesimpulan, serta 5) menyusun laporan dari hasil penelitian.

\section{HASIL DAN PEMBAHASAN}

Berdasarkan hasil penelitian mengenai novel Munjung karya Moh. Ambri, ditemukan hasil deskripsi, struktur cerita, dan unsur antropologi sastra.

\section{Deskripsi Novel Munjung}

Novel Munjung karya Moh. Ambri merupakan buku yang diterbitkeun di Bandung oleh Kiblat Buku Utama pada tahun 2003. Dicetak dalam kertas HVS A5 yang berjumlah 60 halaman. Aksara yang digunakan aadalah aksara Latin dengan menggunakan bahasa Sunda, terdiri 6 bagian cerita (episode), 37 tokoh dengan 5 tokoh utama dan 32 tokoh tambahan, serta alur campuran dengan menceritakan perilaku masyarakat di pedesaan yang masih menganut kebiasaan-kebiasaan munjung atau meminta kekayaan kepada mahluk halus saperti jin, sétan, siluman, dedemit, dan sebagainya.

\section{Struktur Cerita Novel Munjung karya Moh. Ambri}

Teori struktural dalam novel Munjung karya Moh. Ambri menggunakan teori Robert Stanton (2012: 41) yang terdiri atas: 1) tema, 2) fakta cerita (alur, tokoh dan penokohan, dan latar), serta 3) sarana sastra (judul, sudut pandang, dan gaya bahasa). Tema merupakan salah satu ide pengarang dalam mengekspresikan isi cerita yang menjadi inti dari cerita. Menurut Mustaqim (2019: 126) tema merupakan inti masalah yang disampaikan pangarang selama menulis karya. Secara umum tema dalam novel ini berkisah tentang masyarakat pedesaan yang ingin cepat kaya dengan cara munjung atau meminta dan menyembah kepada makhluk selain Tuhan berupa makhluk halus seperti jin, siluman, dedemit, dan sebagainya.

Beragam perilaku manusia yang kaya dengan cara munjung diceritakan oleh tokoh lainnya seperti Salhiam, Mang Uham,Marhapi, Arta, dan Wirja. Kelima tokoh tersebut berbagi kisah tentang hidupnya yang serba kesusahan kemudian mereka bercerita mengenai manusia yang hidup penuh dengan kekayaan hasil dari munjung. Perilaku-perilaku tersebut diceritakan dengan berbagai macam jenis munjung seperti ngipri (menikah dengan siluman ular), ngopét (mengorbankan nyawa orang dengan cara tumbal), ngeték (bertransaksi dengan siluman monyet), muhit bagong/nyegik (ngepet), dan ngingu kecit, (memelihara tuyul).

Berkaitan dengan alur, dalam novel ini pengarang menggunakan alur campuran atau biasa disebut alur maju-mundur. Dalam mengembangkan alur, pengarang membagi cerita dalam novel ini menjadi enam bagian. Setiap cerita memiliki kesinambungan lewat tuturan para tokoh yang berperan penting dalam cerita. Pengarang mengkaitkan masa lalu yang diceritakan kembali oleh para tokoh lainnya pada masa kini. Seperti Salhiam dan Mang Uham yang menceritakan kisah mereka ketika mendengar seseorang yang mempraktekan ritual agar menjadi kaya dengan cara menumbalkan keluarganya sendiri kemudian diceritakan kembali kepada teman-temannya di tempat pos ronda. Di sinilah pengarang menyajikan sistem flashback atau memperlihatkan kembali kejadian-kejadian yang sudah dilalui para tokoh kemudian dikupas kembali dengan obrolan tokoh kepada tokoh lainnya.

Tokoh-tokoh atau pelaku dalam novel ini berjumlah 37 . Dengan lima tokoh utama dan 32 pembantu. Tokoh utama dalam novel ini adalah Salhiam, Mang Uham, Arta, Wirja, dan Marhapi. Sedangkan tokoh pembantu di antaranya seperti Pak Suta, Kuncen, Istam, dan lain-lain. Di samping itu, tokoh berdasarkan sifatnya yaitu ada tokoh protagonis dan tokoh antagonis. Tokoh yang bersifat protagonist yaitu Salhiam, Mang Uham, Arta, Wirja, dan Marhapi. Sedangkan tokoh yang bersifat antagonis yaitu $\mathrm{Pa}$ Suta, Tukang Tahu, Haji Latip, dan Nyi Randa. 
Latar dalam novel Munjung terbagi ke dalam tiga latar yaitu latar tempat, latar waktu, dan latar sosial. Latar tempat terbagi menjadi rumah dan nama daerah yang menjadi tempat pesugihan. Latar yang berada di rumah seperti pangkéng, dapur, kamar, ruang tamu, ruang tengah, tepas, jamban, latar daerah seperti Cirebon, Cimahi, Tasikmalaya, Ciburial, Ciborelang, Bandung, dan Jatiwangi. Latar waktu terbagi menjadi hari, malam, durasi, dan waktu-waktu lainnya. Waltu hari dalam novel Munjung yaitu hari Senin, hari Rabu, dan hari Kamis. Waktu malam seperti subuh, isya, malam Selasa, dan malam Jumat. Waktu berdasarkan durasi yaitu saban mulud, enam tahun, satu tahun satu bulan, dan enam minggu. Dalam novel Munjung terdapat sebutan untuk waktu lainnya yaitu dulu, sekarang, nanti, tadi, dan kemarin. Latar sosial dalam novel Munjung berkaitan dengan status sosial yaitu adanya status sosial haji, penghulu nikah, kuncen, lurah dan kades.

Isi antara judul sudah sesuai dengan gambaran dan tema masyarakat yang munjung kepada makhluk gaib selain ti Tuhan. Judul juga menjadi acuan untuk pembaca agar lebih mudah memahami maksud dan tujuan yang disampaikan oleh pengrang. Dengan begitu, sudah jelas bahwa pengarang dalam menggunakan judul 'munjung' untu mewakili keseluruhan cerita dalam novel ini, tentang perilaku manusia yang menyembah jin dan siluman.dengan novel ini .

Sudut pandang yang digunanakan dalam novel Munjung yaitu sudut pandang orang ketiga - selain ingin bebas mendeskripsikan tokoh, pengarang juga menggambarkan perkembangan tokoh di setiap bagian cerita. Hal ini terdapar dalam novel Munjung di setiap cerita yang dipaparkan melalui nama tokoh.

Gaya bahasa berkaitan dengan ciri khas pengarang dalam menulls cerita. Pengarang menggunakan bahasa sehari-hari yang biasa digunakan oleh masyarakat tertentu. Bahasa yang digunakan tidak terlalu berat dan tidak banyak menggunakan majas atau kiasan. Hal ini menjadi pertimbangan terhadap pembaca supaya lebih mudah mencerna isi cerita dalam novel Munjung. Akan tetapi, ada beberapa kata yang menggunakan majas atau peribahasa dalam menyampaikan isi cerita. Seperti perumpaan orang serakah yang ditandai dengan ucapan tokoh berbunyi "tong sokngarawu ku siku". Peribahasa tersebut ditunjukan kepada orangorang yang tidak pernah merasa cukup atas pemberian Sang Pencipta.

\section{Unsur Antropologi Sastra}

Analisis antropologi sastra dalam novel Munjung menggunakan teori Nyoman Kutha Ratna (2011: 111) yang meliputi : 1) masa lampau, 2) kearifan lokal, 3) folklor (tradisi lisan dan sastra lisan), dan 4) mitos.

Novel munjung adalah sebuah novel yang pertama kali diterbitkan pada tahun 1932 serta ditulis oleh Moh. Ambri pada tanggal 8 September 1892 sampai dengan 5 April 1938. Pengarang memang menceritakan mengenai kejadian yang dialami olehnya pada masa karya tersebt ditulis. Ia menggambarkan keadaan sosial masyarakat Sunda pada zamannya. Oleh karena itu, hingga saat ini kejadian-kejadian dakam novel tersebut tentu saja ditulis sejak dari lama.

Dalam novel Munjung terdapat beberapa cerita yang menunjukan kejadian pada masa lampau seperti tokoh Salhiam dan Mang Uham mengetahui kejadian di masa lalu di mana suatu daerah di Ciburial terdapat haji yang munjung dengan cara ngopét atau menumbalkan nyawa orang lain. Haji tersebut berangkat bersamaan dengan jemaah lainnya. Akan tetapi sesampainya di Singapura, ia tidak melanjutkan ibadahnya ke Mekkah, melainkan menetap di tempat lain. Kemudian setelah tiba masa para jemaah kembali ke kampong halaman masing-masing, haji tersebut barulah ikut kembali bersama rombongan haji lainnya.

Semenjak kejadian tersebut, haji tersebut sering disebut haji bodong atau haji yang tidak jujur dengan istilah lain sering disebut haji boongan. Sesuai dengan antropologi sastra dalam masa lampau, masyarakat zaman sekarang mengetahui kejadian masa lampau dikarenakan seringnya mendengar cerita atau diceritakan oleh orang lain melalui ujaran dari mulut ke mulut yang disampaikan melalui lisanku hiji jalma ka jalma séjén nu ilaharna ngaliwatan omongan (sacara lisan). Masa lampau tidak hilang melainkan disimpan dalam memori diteruskan dalam lamunan baik oleh masyarakat ataupun sejarawan. Hal ini terlihat bahwa dalam novel Munjung menghubungkan unsur masa lampau yang dideskripsikan melalui tokoh masyarakat pedesaan yang masih berpegang teguh pada kepercayaan leluhur di masa lampau.

Arta, "Bulan Puasa harita téh, kuring nganjang ka dulur di Tasikmalaya, lantaran aya perelu badamikeuneun, meunang dua peuting nganjang téh.” (Munjung, hlm. 48) 
Arta bercerita kepada temannya ketika ia berkunjung ke rumah saudaranya di Tasikmalaya. Di sana tengah ramai diperbincangkan mengenai tukang tahu yang dicurigai menjadi babi ngepet karena di daerah tersebut sering kehilangan uang dan sering munculnya babi hutan yang berkeliaran ke pemukiman warga kemudian menghilang setelah diburu. Anehnya, babi hutan itu lari ke tempat tukang tahu tinggal. Kecurigaan warga semakin bertambah ketika dagangan tukang tahu tersebut semakin hari semakin laris manis. Arta menceritakan kejadian tersebut kepada temannya di pos ronda. Kejadian tersebut merupakan pengalaman pribadi di Arta di masa yang sudah lampau satu sudah dilaluinya. Kemduian ia menceritakan kembali di masa sekarang.

Baheula béjana di Bandung aya nu beunghar, nya kitu tara awét bujang, saban taun kudu waé aya bujangna nu paéh saurang, babakuna bujang kakasih, nu sok dibawa sarasiah. (Munjung, hlm. 38)

Arta bercerita kembali kepada temannya bahwa dulu ada seorang bujang atau pembantu yang ditumbalkan oleh majikannya sebagai salah satu syarat tumbal pesugihan yang dilakukannya. Kejadian tersebut pernah terjadi di Bandung. Arta menceritakan kembali kisah tersebut kepada Mang Uham dan Wirja.

Sebagai warisan budaya kearifan lokal perlu dijaga, serta dipelihara. Kearifan lokal mempunyai nilai tambah karena dievokasi melalui khazanah kebudayaan, yang dimiliki oleh leluhur (nenek moyang). memanfaatkan kearifan lokal sama dengan menghargai dan menghormati sekaligus menggunakan kompetensi budaya leluhur.

Dalam karya sastra kearifan lokal merupakan bahasa, baik secara lisan ataupun tulisan. Unsurunsur estetisnya dievokasi melalui bahasa, majas dan gaya bahasa. Analisis sastra diteliti melalui bentuk, yaitu bahasa, sedangkan analisis antropologis dilakukan melalui isi, yaitu muatanmuatan yang ada di dalamnya. Pemilihan para pemimpin daerah yang berasal dari daerah tersebut merupakan contoh lainnya dalam rangka mempertahankan kearifan lokal sekaligus memenuhi hasrat kembali ke masa lampau.

Dalam antropologi sastra, kearifan lokal ditandai dari karya sastra warna lokal. Karya sastra warna lokal biasanya bisa dilihat dari agama, berbagai bentuk kepercayaan, adat istiadat, sistem kekerabatan, sistem pertanian ,sistem ternak, mitologi, tahayul, makanan tradisional, pakaian tradisional, mainan rakyat, jrrd. (Ratna, 2011: 94)

$\mathrm{Ku}$ sabab loba nu ngakal téa, sawaréh mah tacan nepi kana jangji kudu balik, kaburu ku umur. Mayitna diruang sabiasa, tapi peutingna tangtu datang deui, sabab henteu ditarima ku bumi. Dimana datang deui hente digéhgérkeun, tuluy waé dicacag. Bus kana kulit munding atawa kulit sapi, ret-ret dikaput, pék digulung ka palupuh, digarotong ku ahli-ahlina, gejebur ka cai gedé dipalidkeun. Lamun aya nu ngopét paéh, sok pareng turun guntur dibarung $\mathrm{ku}$ angin jeung dordar gelap, cai gedé babanjiran. Upama kaburu ku jangji mah, teu kungsi paéh, sabab ti pamunjungan aya nu nyusulan, mapagkeun, ditumpakkeun kada kuda belang. (Munjung, hlm. 35-36)

Menurut kepercayaan masyarakat, ketika turun hujan disertai dengan adanya petir yang menyambar besar merupakan salah satu tanda bahwa mayat yang mati tidak diterima oleh bumi. Oleh karena itu masyarakat percaya bahwa mayat yang mati tersebut harus dimutilasi kemudian dihanyutkan ke sungai. Adanya cuaca yang buruk tersebut menandakan bahwa di daerah tersebut adanya seseorang yang melakukan perjanjian dengan jin melalui pesugihan ngopét, ia gagal dalam memenuhi syarat pesugihan tersebut kemudian datanglah ajal yang harus memakan nyawanya sendiri. Selain itu terdapat kebiasaan masyarakat Sunda, ada istilah ngaronda atau jaga malam di pos ronda. Hal ini digambarkan oleh tokoh Arta, Salhiam, Mang Uham, Marhapi, dan Wirja yang bercerita di pos ronda sambil bercerita tentang perilaku seseorang yang melakukan pesugihan. Kebiasaan lainnya dengan adanya menyalakan api dengan istilah siduru, kebiasaan tersebut sering dilakukan oleh masyarakat ketika sedang jaga malam sambil membakar singkong dengan istilah mubuy sampeu.

Salhiam, nyéréngéh seuri bari ngagilirkeun tihul, omongna,'Deuh, mun mubuy sampeu, geus asakmeureun."

Mang Uham, "Kudu ka kulisi euy, nyarita,unggal garduh kudu, diteundeunan sampeu keur ronda." (Munjung, hlm. 15)

Folklor terbagi menjadi tiga bagian yaitu: 1) folklor lisan, 2) folklor setengah lisan, dan 3) 
folkor non lisan. Dalam kajian antropologi sastra, folklor lisan setara dengan sastra lisan, sedangkan folklor setengah lisan dan folklor non lisan termasuk tradisi lisan. Sastra lisan merupakan wilayah kajian sastra dan linguistic, sedangkan tradisi lisan merupakan wilayah kajian antropologi dan kajian budaya. Sabagai interdisiplin antropologi sastra mempunyai peranan penting dikarenakan meneliti semua bidang tersebut yaitu kebudayaan, bahasa, begitu juga sastra. Sesuai dengan unsur folklor yang terdapat dalam analisis, adanya sastra lisan dan tradisi dalam novel Munjung.

"Nun Sang Ratu Cindéwelang,
nu ngageugeuh sunyaruri,
ibu rama para putri
kula seja babakti."
"Nun Sang Ratu kaula amit matur,
seja nyusul catur nu kapungkur,
pasang subaya baheula,
nu ragrag ka kaula."
"Nun Sang Ratu terah Maraja Sakti
kaula ngadeuheuskeun lalaki sayakti,
picarogéeun Nyai Putri. (Munjung, hlm 23-
25)

Tokoh Pa Kuncen membacakan mantra untuk memanggil sang penunggu, jin ipri (siluman ular). Pengarang mendeskripsikan salah satu tokoh dalam cerita yaitu Pa Kuncen yang membaca mantra untuk memanggil sang penunggu. Mantra tersebut merupakan bagian dari folklor non lisan, yang kemudian menjadi sastra lisa. Hal tersebut karena kini sudah diarsipkan. Oleh karena itu mantra-mantra yang dibacakan oleh kuncen dideskripsikan pengarang sebagai salah satu syarat memanggil jin penunggu. Hal tersebut hanya bisa dilakukan oleh kuncen sebab hanya kuncenlah yang bisa membacakan mantra tersebut.

Dalam novel Munjung pengarang mendeskripsikan beberapa tradisi lisan yang dilakukan oleh masyarakat seperti ritual alam gaib, ritual malam Selasa dan malam Jumat, dsb.

Sasajénna puncak manik, duwegan, rampé, kekembangan, minyak seungit, malah aya roti, kuéh-kuéh, tangkuéh, citéh jeung gula batu, seupaheun sapepekna katut minyak lambéna, roko daun jagong tujuh siki. (Munjung, hlm. 23)

Sebelum melakukan pesugihan, harus sedia berbagai macam bahan dan alat untuk melakukan ritual pesugihan seperti buah-buahan segar, kemenyan, alat perkakas dsb. Bentuk ritual tersebut merupakan salah satu tradisi yang dilakukan oleh seseorang yang akan munjung atau meminta kekayaan kepada jin dan siluman yang akan disembahnya. Dalam praktek pesugihan ngipri kuncen meminta kepada pelaku agar menyediakan benda yang dianggap keramat seperti yang telah disebutkan sebelumnya guna memperlancar praktikan dalam pesugihan tersebut.

Pengarang mendeskripsikan berbagai tata cara atau tardisi yang dilakukan oleh para tokoh dalam bentuk ritual. Selain itu tradisi lainnya yang harus dilakukan yaitu dengan cara melakukan syarat yang telah disetujui oleh kedua belah piha seperti menikah dengan siluman ular, menumbalkan anggota keluarga, menjadi siluman monyet, menjadi babi ngepet, dan memelihara tuyul. Hal tersebut merupakan syarat yang harus dilakukan dalam pesugihan sebagai imbalan untuk mendapatkan kekayaan yang diinginkannya.

Mitos merupakan kejadian yang belum tentu kebenarannya, hanya sekadar dongeng atau cerita yang disampaikan melalui omongan. Oleh karena itu, mitos masih dipertanyakan kebenarannya. Akan tetapi, kini mitos telah menjadi pegangan yang berkaitan dengan kenyataan. Contohnya seperti tokoh dalam novel Munjung yang melakukan pesugihan dengan siluman. Hal tersebut memang ada yang menyebut mitos, tapi di sisi lain masih ada yang percaya bahwa kejadian tersebut memanglah nyata adanya. Dengan kata lain, mitos akan menciptakan mitos yang baru. Mitos manusia yang melakukan pesugihan bukanlah sekadar omongan semata. Dalam novel Munjung terdapat mitos yang diperacaya oleh masyarakat pada zamannya namun masih dipertanyakan di masa sekarang.

Cék ki lanceuk 'Piraku. Bagong ingu mah moal enya bisa ngiles. Geus lila puguh Akang téh ngadéngé béja, majar tukang tahu nyegik."

Dina malem Salasa, malem Jumaah kudu turun ti imah, ngégél rokrak keur sisihungan, monyongna ku cangkir dibekemkeun kana sungut. Di taneuh susungkur lebah nu bécék, ngala cacing. (Munjung, hlm. 49)

Seseorang yang melakukan pesugihan nyegik harus melakukan ritual lainnya pada malam Selasa atau malam Jumat. Hingga saat ini mitos mengenai malam Selasa dan malam Jumat 
merupakan malam yang dianggap keramat. Menurut kepercayaan, mitos dengan adanya malam tersebut dijadikan sebagai salah satu malam aktifnya para makhluk halus.

Kuncén mapatahan ka nu munjung prakprakanana di imah sarta masinikeun perjangjian. Sanggeus liwat tujuh taun, mandi samulud sakali, sarta baris beunang buntut, sataun sabuku ramo. Dimana buntut geus sarua jeung buntut monyét, manéhna aya nu néang utusan ti $\mathrm{Ki}$ Mandahong. Engké ari jol ka pamunjungan téa, rob dirubung $\mathrm{ku}$ monyét-monyét di dinya, minangka dibagéakeun, ngahormat kanu anyar datang. (Munjung, hlm. 44)

Seseorang yang melakukan pesugihan nyupang (bertransaksi dengan siluman monyet) akan dijemput ketika ekor yang tumbuh panjangnya sudah mencapai ukuran ekor monyet. Hal tersebut tidak boleh ada pelanggaran terhadap janji yang sudah disetujui oleh orang yang melakukan transaksi. Ketika waktunya tiba, dimana sang pelaku pesugihan harus ikut bersama monyet lainnya kemudian ia akan berubah menjadi siluman monyet untuk selamanya

Mitos yang terdapat dalam novel Munjung merupakan gambaran masyarakat Sunda pada zaman dahulu yang dicertikan melalui lima tokoh, alhiam, Mang Uham, Arta, Wirja, dan Marhapi. Masyarakat yang ingin cepat kaya biasanya melakukan pesugihan di waktu tertentu, misalnya mandi satu mulud sekali, menumbalkan keluarga satu tahun sekali, dan melakukan praktek ritual pada malam Selasa dan malam Jumat.

\section{KESIMPULAN}

Novel Munjung karya Moh. Ambri terdiri atas 6 bagian cerita (episode), 37 tokoh dengan 5 tokoh utama dan 32 tokoh tambahan, serta alur campuran dengan menceritakan perilaku masyarakat di pedesaan yang masih menganut kebiasaan-kebiasaan munjung atau meminta kekayaan kepada mahluk halus saperti jin, sétan, siluman, dedemit, dsb.

Struktur cerita novel Munjung karya Moh. Ambri terdiri atas tema (sosial), berkisah tentang masyarakat pedesaan yang ingin cepat kaya dengan cara munjung atau meminta dan menyembah kepada makhluk selain Tuhan berupa makhluk halus seperti jin, siluman, dan dedemit. Alur yang digunakan dalam novel ini yaitu alur campuran atau biasa disebut alur majumundur yang terbagi menjadi enam bagian cerita. Tokoh-tokoh atau pelaku dalam novel ini berjumlah 37 . Dengan lima tokoh utama dan 32 tokoh pembantu. Serta tokoh protagonist dan tokoh antagonis. Latar dalam novel Munjung terbagi ke dalam tiga latar yaitu latar tempat, latar waktu, dan latar sosial; serta 3) sarana sastra (judul, sudut pandang, dan gaya bahasa). Judul dengan kata "Munjung" mewakili seluruh tema dan isi dalam bagian cerita beserta digunakannya sudut pandang orang ketiga. Dalam penggunaan bahasa tidak banyak menggunakan peribahasa, pengarang lebih banyak menggunakan bahasa sehari-hari.

Unsur antropologi sastra dalam novel Munjung meliput masa lampau (masa lalu yang diceritakan oleh satu tokoh kepada tokoh lainnya seperti menceritakan dulu, kemarin, tahun lalu, bulan lalu, dan tadi). Kemudian kearifan lokal (kepercayaan masyarakat, tradisi, kebiasaan, dan agama. Lalu foklor (tradisi lisan dan sastra lisan), seperti mantra, peribahasa, bahasa, dialek, ritual, dan adat istiadat. Serta yang terakhir adalah mitos (kecurigaan, kepercayaan, kecintaan, dan takdir)

\section{REFERENSI}

Adam, A. (2015). Karakter Tokoh Dalam Novel Kau, Aku Dan Sepucuk Angpau Merah Karya Tere Liye. Jurnal Humanika No. 15, Vol. 3, Desember 2015 / ISSN 1979-8296. http://ojs.uho.ac.id/index.php/HUMANIKA/ article/view/584

Ambri, M. (2003). Munjung. Bandung: Kiblat Buku Utama.

Andriyani, S. (2017). Unsur Intrinsik Novel $5 \mathrm{~cm}$ Karya Donny Dhirgantoro. Jurnal UNJA. Diakses dari http://repository.unja.ac.id/1403/1/A1B1100 99-ARTIKEL.pdf pada tanggal 20 Januari 2019.

Arikunto, S. (2009). Manajemen Penelitian. Jakarta: Rineka Cipta.

Ayuningtyas, D. (2016). Nilai Budaya Pada Novel Gugur Bunga Kedaton Karya Wahyu H.R: Kajian Antropologi Sastra Dan Implementasinya Dalam Pembelajaran Sastra Di SMA. (Thesis). Universitas Muhammadiyah Surakarta. Diakses dari https://prints.ums.ac.id/40563/ pada tanggal 12 November 2019.

Djirong, S. (2014). Kajian Antropologi Sastra Cerita Rakyat Datumuseng dan Maipa 
Deapati (Anthropology Of Literature Analysis Datu Museng and Maipa Deapati Folklore) Sawerigading, Vol. 20, No. 2, Agustus 2014.

Éndraswara, S. (2013).Metodologi Penelitian Antropologi Sastra. Yogyakarta: Universitas Negeri Yogyakarta.

Isnéndés, C.R. (2010). Teori Sastra. Bandung: JPBD FPBS-UPI.

Mustaqim, F. (2019). Naskah Drama "Hutbah Munggaran di Pajajaran" Karya Yus Rusyana (Kajian Struktural dan Semiotik). Jurnal Lokabasa Vol. 10, No. 1, April 2019. https://ejournal.upi.edu/

Prabowo, A. (2013). Analisis Pemanfaatan Buku Elektronik ( E-Book ) Oleh Pemustaka Di Perpustakaan Sma Negeri 1 Semarang. Jurnal Ilmu Perpustakaan Volume 2, Nomor 2, Tahun 2013. https:/ejournal3.undip.ac.id/index.php/jip/art icle/view/3123

Ratna, N.K. (2011).Antropologi Sastra PerananUnsur-unsurKebudayaandalam Proses Kreatif. Jakarta. Pustaka Pelajar.

Saddhono, K., Ridwan, M., Suherman, A., Anwar, K., \& Putri, N. Q. H. (2020, July). The Development of Interactive E-book of Teaching Indonesian for Speaker of Other Language (TISOL) Containing Local Wisdom with Scientific-Thematic Approach. In Journal of Physics: Conference Series (Vol. 1573, No. 1, p. 012002). IOP Publishing.

Stanton, R. (2012). Teori Fiksi Robert Stanton. Yogyakarta: Pustaka Pelajar.

Sudikan, S. (2007). Metode Penelitian Sastra Lisan. Surabaya: Citra Wacana.

Suherman, A. (2019). Literacy Tradition of Sundanese Society-Indonesia. International Journal for Innovation Education and Research, 7(3), 262-271. https://doi.org/10.31686/ijier.Vol7.Iss3.1377.

Wahyuningsi, E. (2018). Pergeseran Nilai Budaya Jawa Dalam Novel Canting Karya Arswendo Atmowiloto: Suatu Kajian

Antropologi Sastra. Jurnal Kata: Vol. 2, No. 2, Oktober 2018.

https://ejournal.kopertis10.or.id/index.php/kata/a rticle/view/3618 